\title{
HAY UNA DISCUSIÓN EN EL BARRIO...
}

Hernán Toro (herntoro@univalle.edu.co)

Profesor Titular

Escuela de Comunicación Social, Facultad de

Artes Integradas, Universidad del Valle

(Entrevista a Alejandro Ulloa a propósito de su libro «La salsa en

discusión", publicado por la

Editorial de la Facultad de Humanidades de la Universidad del

Valle, Cali, diciembre de 2008).

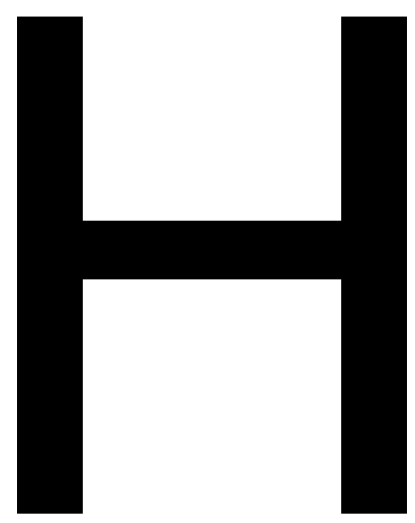

ernán Toro (en adelante T). Tras 20 años de haber publicado «La salsa en Cali» aparece «La salsa en discusión». Qué es lo nuevo en este libro, a qué tipo de necesidad responde, cuáles son las líneas de continuidad y de ruptura con respecto al primero. Alejandro Ulloa (en adelante U). Después de haber publicado « $L a$ salsa en Cali» seguí trabajando el tema de la salsa y ampliando mi visión hacia otros subtemas dentro del campo de la investigación música popular y ciudad, en particular ciudad y culturas populares urbanas. Obviamente, ha habido cambios vertiginosos en lo tecnológico, en lo cultural, en la música, en la ciudad de Cali y en uno también. Yo quería publicar la tercera edición de «La salsa en Cali». Comencé ese trabajo hace 10 años pero a medida que me fui metiendo me di cuenta que era complicado pues cuando integraba algo nuevo se afectaba una parte del texto, se desacomodaba la argumentación: era inviable. Al mismo tiempo hacía investigación de campo sobre prácticas y espacios de recepción de la salsa en Cali, leía, me actualizaba sobre otros aspectos de la salsa. Y cada que sistematizaba la observación terminaba por no encajar con el texto. Y al ver el grado de complejidad me descorazonaba. Trabajaba por tiempos. En el 2000 trabajé un año haciendo trabajo de campo y lo dejé 2 años. En el 2003 me reanimé gracias a ciertas ráfagas de energía. Pero también me encontraba sujeto a los vaivenes del tiempo por mis responsabilidades como profesor de la Universidad del Valle. En el 2006 lo tomé bien en serio pues ya "La salsa en Cali» iba a cumplir 20 años. Lo primero que hice fue copiar las 650 páginas del libro porque no lo tenía en archivo 
digital, hubo muchos errores, y bueno... Comencé a hacer insertos pero eran anexos forzados.

T. Superdispendioso.

U. Sí, notas al margen, información por confirmar. En el 2006 asistí en Nueva York como invitado a un festival de coleccionistas, preparé una ponencia, «La salsa en tiempos de reguetton». Fue una experiencia muy estimulante porque aparte de encontrarme con gente de todos los países latinos pude hacer entrevistas, recorridos por Spanih Harlem, el Barrio latino, por el South Bronx, por Harlem, y tomar información sobre el terreno, fotos, entrevistas sobre temas inconclusos. Me vine con ese material y nuevos bríos para continuar el último trimestre de 2006. Agregué cosas y comencé el 2007. Animado por ese trabajo y gracias a una coyuntura favorable (me pidieron un trabajo de la Secretaría de Cultura de la ciudad de Cali consistente en una especie de circuito de la salsa en la ciudad, una especie de diagnóstico que yo, entre otras cosas, ya había adelantado bastante en la investigación empírica). Bueno, me dije, ya no se trata de un trabajo para mí sino con un objetivo más amplio. Entonces continué recorriendo todos los sitios de música antillana y salsa que hay en Cali, con

una metodología que yo mismo elaboré a partir de categorías descriptivas, clasificatorias, a partir de indicios cuantificables. Puse todo esto en un

mapa de la ciudad e hice inferencias sobre estratificación social, ejes de recepción y consumo, públicos que asisten, mujeres, hombres, etc. Lo hice a lo largo del 2007. Entonces allí sí me dije muy seriamente que debía hacer la tercera edición de «La salsa en Cali». Un día, hablando con....vos, vos me dijiste: «esto no es la tercera edición sino un libro nuevo». Yo no lo había pensado, aunque lo había intuido pero no lo había decidido y estaba en la indecisión. Cuando me dijiste «este es otro libro", pues me dije, cómo es posible, sí, es otro libro.

T. La fuerza de la evidencia es enceguecedora. U. Sí, la cosa tan obvia. Sí es otro libro. «La salsa en Cali veinte años después», o algo así. Bueno, seguí trabajando con esa idea, tercera edición, revisando, corrigiendo, tomé decisiones drásticas. Después estaba con otro amigo, el profesor Agustín Lao, de Puerto Rico, y después de una larga conversación me dijo «tenés dos libros en uno». La primera parte es «La salsa en discusión» 
(que tenía 35 páginas), la segunda es «La salsa en Cali». Me dije, verdad, hombre. También era obvio pero no lo había advertido. «Por qué no lo publicás como dos partes independientes». En efecto, me puse a leer el documento de las 35 páginas pero evidentemente no daba para un libro.

T. ¿Esas 35 páginas más las otras leídas por Agustín eran un material totalmente distinto a «La salsa en Cali»?

U. Totalmente no. Se habían desprendido de allí, pero el nuevo libro se había desprendido de 5 páginas de «La salsa en Cali». A comienzos de 2007, esas pocas páginas se me volvieron casi incontrolables. De 35 páginas llegó a las 270 , que es el libro actual. Tales hechos me obligaron a suspender el proyecto «La salsa en Cali», Tomo II, o veinte años después, proyecto que voy a retomar ahora.

T. En resumen: de «La salsa en Cali», el libro de hace 20 años, surge un material que son dos libros, uno, «La salsa en discusión», que es el que acaba de publicarse, y otro que sería más una continuidad temática con el de hace 20 años.

U. Y que se llamaría "La salsa en Cali, 20 años después», o algo parecido. En este en proyecto voy a eliminar todo lo que se refiere a la historiografía de la música cubana.

T. Por qué.

U. Por varias razones. La primera, los cubanos han escrito mucho sobre ello en los últimos 20 años, ha habido una revisión crítica de la historiografía de la música popular cubana. Sobre todo en un libro que escribió Leonardo Acosta, una colección de 16 ensayos hechos en los últimos 10 años donde cuestiona seriamente muchas de las tesis pilares de esa historiografía, que fueron las fuentes en que yo bebí.

T. Claro, eso está desactualizado.

U. Exactamente. Entonces no tiene sentido que siga repitiendo lo mismo; aunque allí hay observaciones originales pues yo no me apoyé sólo en los cubanos de los 70 , los 60 , los 50 , sino que también había sacado conclusiones de mis propias audiciones y sobre todo de la presencia de la música cubana en Cali. Eso sí no lo han hecho los cubanos. Yo utilizaba los textos de las canciones (de la Sonora Matancera, de Daniel Santos) en el contexto caleño. En eso el libro puede seguir teniendo cierta vigencia, aunque también, por haber sido publicado en los 80 , estaba escrito para una generación que disfrutó con la Sonora, con Daniel, con Celia Cruz; esa generación tiene ya 20 años más. (Risas).

T. (Risas) Algunos hasta están muertos (Carcajadas). Bueno, una curiosidad: esa segunda parte cuántas páginas tiene en su estado actual.

U. Creo que tiene unas 200.

T. Voluminoso. Cuánto tiempo te va a tomar.

U. No, este año. Para diciembre. Está bastante adelantado. De «La salsa en Cali», el libro de hace 20 años, dejo unos capítulos relativos a Cali. Dejo el capítulo sobre los medios de comunicación pues hay referencias al origen de la salsa en la radio caleña, que yo llamo «radio salsa». Lo quiero dejar por su importancia como documento histórico. También tengo anotaciones del 2000 sobra la radio salsa. Incluiré lo que haga este año también. El capítulo 11, «Se prende la rumba», que me parece el más importante pues hago una historia cultural de la fiesta popular caleña ligada a la música antillana y a la salsa, también lo dejo. Va a quedar completo. $Y$ posiblemente agregue otras cosas ya que he encontrado crónicas que hablan del baile en Cali, de 1909, de 1930, que voy a incorporar. T. Recuerdo la referencia en «La salsa en Cali» a la novela de Palacios, ¿cómo se llama?...El Alférez Real. La gente se va de rumba para la ciudad.

U. Sí, desde la hacienda Cañasgordas.

T. Es una vieja historia esa de la rumba en Cali, ¿no?

U. Sí, es una vieja historia. El amo blanco, el hijo del hacendado, va a caballo con su peón, que había sido su esclavo, y le pregunta si habrá una fiesta allá en el Vallano, el actual San Nicolás. El esclavo todo animado le dice que vayan. El

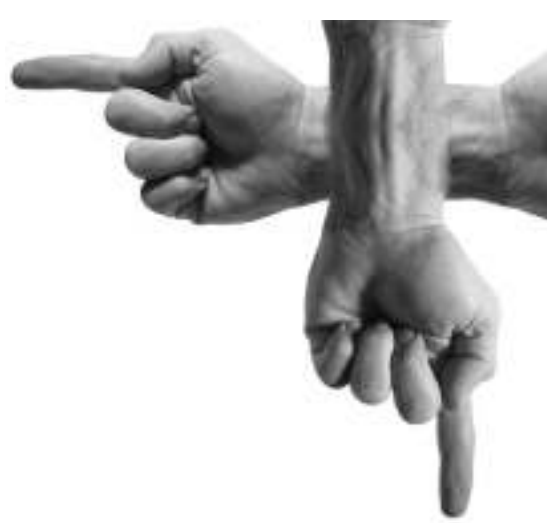


hijo del hacendado le responde con miedo que ya van a ser las 9 y que a esa hora tocan la campana para el toque de queda. Hay que resguardarse. Lo que indica que el barrio San Nicolás era caliente ya desde entonces.

T. Peligroso.

(RISAS)

U. Además oscuro porque la gente se alumbraba con velas en un contexto rural. Me imagino esos solares, casa viejas a la orilla del río, la zona del Piloto. Eso debió haber sido bastante agitado.

T. Ja, ja, ja. Por decir lo menos.

U. Por decir lo menos. Ja, ja, ja. Entre otras cosas porque en el siglo XX, en los años 30 , se siguen haciendo fiestas en los patios de esas casas de San Nicolás.

T. Al estilo cubano. Y brasilero.

U. Sí, fiestas del solar, que creo que son los «champús bailables», con la vitrola de moler, con el rollo de las primeras tecnologías de la industria discográfica. Pero me falta documentar del 30 para atrás. De los primeros 30 años del siglo XX tengo referencias de ciertos bailes, pero son de la élite. No son populares.

(Silencio)

T. Es un trabajo gigantesco. Un proyecto de vida. U. Sí, sí, es un proyecto de vida. Sin duda. (Silencio)

T. ¿Existe en Colombia un trabajo semejante sobre la incidencia de la salsa en relación con grupos sociales, con barrios? 0 tu trabajo es pionero.

U. Hasta donde sé es pionero. Cuando comencé en el 81,82 , nadie había hecho nada sobre salsa. Sobre folklore sí, pero sobre música popular entendida como música urbana, mediatizada, con las tecnologías de radiodifusión de la industria discográfica, sobre eso no. Creo que hay trabajos en Barranquilla, a lo mejor en Cartagena y otras ciudades colombianas, pero no los conozco realmente.

T. Sobre lo folklórico.

U. Sí, sobre lo folklórico. Algo debe haber sobre la salsa pero enfocado más por el lado de biografías de músicos.

T. Información, no análisis.

U. Información, no análisis de un proceso, de una historia cultural en una ciudad. Yo no conozco. Puede que haya trabajos de grado en universidades, ensayos publicados. Sé que hay sobre el vallenato, la champeta. En fin. Sobre la salsa pensada como estudio cultural, serio, riguroso, no, no conozco.

T. Bueno, Alejandro. El asunto principal del libro actual, «La salsa en discusión», es el nacimiento de la salsa en Nueva York. ¿Podés hacer una descripción somera de ese fenómeno?

U. Sí. La primera gran obra es la de César Miguel Rondón escrita hace 30 años en Venezuela.

Rondón sitúa el nacimiento de la salsa en el barrio latino de Nueva York a finales de los $60 \mathrm{y}$ comienzos de los 70. Habla del barrio en general pero no especifica cuál es el barrio, el «barrio latino» es una denominación muy genérica. El que viva allá sabe a qué se refiere, pero al venezolano, al colombiano, a cualquier latino que no conozca el barrio latino de Nueva York no le dice mayor cosa. En mis visitas desde los años 90 motivado por la historia de la salsa siempre me pegaba mis caminadas, mis perdidas, en el metro, en las calles, buscando sitios, referencias. Fui acumulando información, historizando ese barrio. Rondón no lo había documentado a pesar de que lo había mencionado. Cuando enfrento esta tarea del 2006 para acá encuentro que puertorriqueños americanizados y newyork-ricans habían hecho tesis doctorales sobre el barrio. T. De qué año es el libro de Rondón. U. 1979. En los 80 hay trabajos hechos por puertorriqueños. Sobre todo en los 90 hay trabajos publicados en inglés que han estudiado el problema de la migración puertorriqueña a Nueva York y la configuración de las comunidades puertorriqueñas y newyork-riqueñas. Qué hago yo. Hago entrevistas a músicos y a cronistas que se formaron allí, complemento lo que otros han hecho. El barrio latino es el Spanish Harlem, una sección de Manhattan; está en el east side, lado oriental de Manhattan, al suroriente del Harlem negro, donde está el teatro Apolo, ¿conocés?, bueno, entonces a la derecha, todo eso es el Spanish Harlem, desde la 97 hasta la 130 es el Harlem hispano. Allí hay un río, que es el Harlem river, y al otro lado está el Bronx y hay una parte que es el South Bronx que es donde se desarrolla la cultura hip hop. También en South Bronx hubo mucha presencia de músicos caribeños, newyorkricans, puertorriqueños, cubanos neoyorkinos pues muchos de los clubes donde tocaban estaban en el South Bronx. Entonces siempre se ha hablado del barrio latino como si fuera el Harlem Spanish y se ha dejado de lado el South Bronx. Dos investigadoras puertorriqueñas que hicieron sus tesis doctorales en Estados Unidos han reivindicado el South Bronx y le han dado su importancia. Para mí el barrio es un continuo. Hay una continuidad sociocultural entre el Harlem Hispano y el South Bronx. Muestro ese ir y venir, esa transhumancia entre los dos barrios de los músicos y de la música aunque efectivamente muchos estén más ligados a uno u a otro. En 
realidad es un continnum pues difícilmente se puede trazar una frontera culturalmente hablando. Ese es un punto. El otro que yo desarrollo es que todos los estudios que conozco ubican el nacimiento de la salsa a finales de los 60 y comienzos de los 70 . Yo lo corro 10 años para atrás, lo pongo a finales de los 50 y comienzos de los 60. Entiendo que sea de difícil aceptación pues la gente dice que nace después de la pachanga y después del bogaloo. La pachanga surge en el 58 y dura hasta el 65. Es el apogeo fuerte, el que vivimos en Cali. Después, en el 66 surge el boogaloo. El boogaloo desplaza a la pachanga en Nueva York pero no en Cali. Aquí la pachanga sigue vigente después de 50 años. La única parte del mundo en que seguimos siendo pachangueros. Y el boogaloo en Nueva York desplazó a la pachanga. Desde Rondón en adelante todos conservan la misma secuencia: la salsa surge después del boogaloo, que surge después de la pachanga. Entonces para ellos ni el boogaloo ni la pachanga hacen parte de la salsa. Se trataría de una música distinta. Y además la entroncan con el fenómeno de Fania porque creen que la salsa fue un invento suyo. Como ésta fue el gran emporio que capitalizó todo (cogió los mejores músicos, las mejores orquestas, los mejores cantantes, los mejores directores, los agrupó, formó una empresa multinacional, eclipsó casas disqueras, dejó por fuera a muchos músicos que no se sometieron a sus condiciones). Produjo un boom, produjo dos películas, «Nuestra cosa latina» y «Salsa», que son del 70 y del 72 .

Entonces todo mundo piensa que la salsa nació con la Fania en el 70 y de ahí en adelante quedó en el imaginario colectivo que salsa igual Fania. Yo ubico la salsa a finales de los 50 y comienzos de los 60. E incluso considero el boogaloo y la pachanga como parte del nacimiento de la salsa porque son los mismos músicos: Eddie Palmieri toca pachanga, Charlie Palmieri toca pachanga, boogaloo y los demás géneros que integran la salsa.

T. Es la producción posterior al 65 la que recoge la herencia de la pachanga y del boogaloo. $U$. Antes de reaccionar a este comentario diría otras cosas. Como en toda las músicas, hay continuidades y rupturas. Hay ciertos elementos de continuidad presentes en la manera de asumir y de ejecutar los instrumentos. Voy a ir un poco más atrás porque la pregunta es de fondo. A ver, hasta 1958, 60, la música cubana se había hecho de acuerdo a unas estructuras rítmicas, melódicas y armónicas fijas, que son los géneros. ¿Sí? Más o menos fijas, estables: un bolero era un bolero y se tocaba de cierta manera. $\mathrm{Y}$ los instrumentos tenían que ser ejecutados de cierta manera para que no se salieran porque si no ya no era un bolero. Una guaracha se hacía con ciertas características porque si no ya no era una guaracha. Un danzón, lo mismo. Por ejemplo, el danzón era con violines, flautas, piano, contrabajo o bajo, y tumbadoras. Pero las tumbadoras tenían que estar muy amarradas al diseño rítmico del género danzón. Entonces el conguero no podía repentizar, volar.

T. Tenía que responder a un formato.

U. Un formato predefinido, cumplía una función predeterminada. Quizás otros instrumentos podían improvisar. La música cubana por géneros estaba muy delimitada y eran formatos muy respetados, lo que se conserva hasta mediados de los 50. En Cuba hasta los 60 y hasta después. Pero en Nueva York eso se comienza a romper a mediados de los 50. Entonces cuando llega la charanga, que es una formato instrumental, un tipo de orquesta que tiene 2 ó 4 violines, flauta, piano, bajo, congas y timbal, ese formato llega a Nueva York y se impone. Gilberto Valdés trabaja ese formato en 1952 pero no le va muy bien. Después llega Fajardo y hace ese baile en el Waldorf Astoria para la campaña presidencial de John Fitzgerald Kennedy, y la presencia de Fajardo anima a todo el mundo con la pachanga y la charanga. Entonces algunos músicos del Harlem hispano que ya están tocando en cuartetos de barrio comienzan a pensar que no pueden sostener una charanga por el número de músicos y por otras razones. Buscan alternativas y encuentran en el vibráfono (un instrumento con mucha historia en el jazz) un instrumento cómodo, fácil, flexible para asumir la melodía. Pero ya no se le puede llamar charanga; es otra cosa, un sexteto, quinteto, cuarteto que tiene vibráfono, piano, conga, bajo y bongó o timbal. Entonces, para mí ya empieza a nacer la salsa. Hay una ruptura con el formato orquestal de la charanga. Ese formato, que había tenido vigencia por 60 años en Cuba, se diversifica en variantes: unos le meten vibráfono, otros le meten trombón, trompeta, saxo, es decir, una serie de exabruptos con respecto al formato tradicional, una verdadera transgresión. Ya no se puede llamar charanga. Otros le meten guitarra eléctrica, como Randy Carlos y El Sexteto la Plata; Joe Quijano le mete trompeta, Eddie Palmieri mete trombón, trompeta y flauta. T. Pero el decisivo era el vibráfono. U. En ese momento sí. Tito Puente tocaba el vibráfono en el 48 con sus Picadilly Boys, Joe Loco en el 50, 52 incorpora a Luis Ramírez, su sobrino, como el vibrafonista de su grupo. Charlie 
Palmieri crea en el 49 el conjunto Pin Pin con vibráfono. Y Joe Cuba, viendo esos ejemplos, decide en el 55 armar su conjunto sexteto y en vez de violines y flautas mete un vibrafonista del barrio y arma su sexteto con amigos de barrio.

T. ¿Significa eso que la introducción del vibráfono obedece a razones económicas dado que sostener el formato clásico de la charanga era costoso?

U. No es la única razón. Está también por un lado el mayor número de músicos, de otra parte la especialidad de los violinistas. De otra parte, el vibráfono era un instrumento que ya sonaba en el barrio, con varios grupos y que con él se podía montar un sexteto. Pero también por la presencia del vibráfono en los grupos de jazz y particularmente por la influencia del jazzista y vibrafonista Cal T. Jader en los años 50.

T. El vibráfono aportaba flexibilidad.

U. Sí. Y le permitía explorar otra sonoridad. Además como se tocaba en clubes de barrio, en escuelas, en bares, lugares pequeños, eso facilitaba la contratación, el desempeño de los músicos. Antes de que se volvieran famosos y pasaran a los grandes clubes, claro está. Ese es un elemento. El otro elemento clave en el nacimiento de la salsa es la ruptura con la manera de producción de los géneros cubanos, cuando en Nueva York se comienza a hacer transgresiones al pasar de un género a otro sin pedir permiso, no importa si me salgo de un son y me meto a una guaracha.

T. Hay una intertextualidad.

U. Exacto. Hay una relación transgenérica que va ganando más dinámica a medida que se desarrollan los 60. La salsa que se hace después del boogaloo desarrolla más esos cruces intergenéricos y esas transgresiones que se habían iniciado con Joe Cuba y habían continuado con Eddie Palmieri, Charlie Palmieri, Johnny Pacheco en el 59, 60, 61 y 62. Esas relaciones transgenéricas las desarrolla la salsa, las continúa elaborando en los 60 . Al hacer esa ruptura de los límites, ciertos instrumentos están más libres para ser ejecutados con mayor flexibilidad. Si en el danzón la tumbadora se tocaba de cierta manera, ahora al mezclar danzón con pachanga, danzón con guaracha o pachanga con son, le das libertad pues ya la tumbadora se zafa del esquema y comienza a tener libertad. Eso lo hacen los músicos a finales de los 50 y lo continúa la salsa después del boogaloo.

T. Hay también razones industriales, quizás, como salirse de los 3 minutos de grabación.

U. Hay un tercer ingrediente. Para mí son básicamente tres. Uno, la ruptura del formato que sale de la charanga. Dos, la libertad en el uso de ciertos instrumentos pues ya no están supeditados al esquema de los géneros. Tres, de las más interesantes, el acelere del tempo musical. Ese acelere es para mí fundamental. Yo lo había captado intuitivamente escuchando algunas canciones pero no le había puesto mayor cuidado. Si estoy en lo cierto, como lo espero, es una tesis novedosa e inédita pues, con la ayuda de un músico amigo aquí en Cali, comparo en el laboratorio las mismas canciones grabadas en Cuba y luego grabadas en el 58, 59 en Nueva York: la diferencia en el tempo es considerable; eso se mide en pulsaciones por minuto; es lo que los americanos llaman el up tempo. Es algo que se puede constatar empíricamente.

T. Sin hablar de la exacerbación del acelere en Cali.

U. Sí, pero esa es otra cosa, tiene que ver con la velocidad. Nosotros lo hicimos en el consumo y en la recepción, no en la producción. Lo de la aceleración es un fenómeno que aparece en Nueva York y, hasta donde sé, en Cuba no se había dado. Para mí ocurre en el 56, 57, con el Mambo of the pines, un mambo acelerado, que no se parece en nada al mambo de Pérez Prado.

T. Mambo de pino es grabado con el acelere ya interiorizado, digamos natural, con la velocidad que se sentía socialmente.

U. Sí. Las que son comparables son El Manicero que graba Cachao en el 58 con el formato de una agrupación típica cubana para darle todo el color que remita al son típico cubano. Cuando uno compara ese Manicero con el que hace Charlie 
Palmieri con la Allegre all Stars cantado por Chirivico Dávila en el 60, es una cosa impresionante. Claro que el cambio no es solamente en el tempo sino también en la instrumentación. El Manicero de Palmieri tiene trombón, que le da una agresividad la berraca, parece el pito de un camión en Nueva York, en Sao Paulo o en cualquier ciudad de tráfico pesado.

T. A qué atribuís esa aceleración.

U. Le voy a preguntar a Cheo Feliciano, a Willie Rosario y a varios músicos ahora que vaya a Puerto Rico. Para mí esa aceleración es inconsciente, fluía de la subjetividad pues ese acelere es parte de una nueva forma de vivir y de percibir el tiempo en una ciudad tan acelerada y tan agitada como Nueva York en los 60. La evidencia del tempo hace parte de una nueva subjetividad con respecto a otras maneras de vivir y de sentir el tiempo en regiones no aceleradas del mundo. Si te vas a una playa en la costa Pacífica donde la gente vive con las mareas, las fases de la luna, el oleaje, el viento..., el tiempo es otro. Pero en Nueva York es distinto. Esa generación (la que crea la salsa) es acelerada, con latinos, newyork-ricans, puertorros que viven a millón, que tienen que rebuscarse, deben guerrear, pelear para sobrevivir en condiciones adversas. Así es el barrio y en esas condiciones nace la salsa.

T. ¿El consumo de la droga responde al mismo acelere? U. Probablemente. Pero creo que lo de la droga es más de los 60 para adelante. En ese momento ese acelere tiene que ver más con el aceleración de la vida urbana provocada por el desarrollo del capitalismo, en una nueva fase posterior a la segunda guerra mundial.

T. Sobre eso te iba a preguntar. ¿Encontrás una asociación entre esa aceleración de la música y el rendimiento capitalista que exige mayor productividad en la misma unidad de tiempo?

U. Sin duda, sin duda. Para mí, sobre todo después de la segunda guerra mundial, que es una época de desarrollo, de bonanza, de más producción, mas billete circulando, más mercancías en circulación, más consumo... Y también más gente emigrando hasta el corazón de ese sistema.

T. Menos tiempo.

U. Sí, menos tiempo para todo. Los músicos tienen eso en su inconsciente y cuando van a tocar en Nueva York no lo hacen con la pausa del cubano que está allá en Santiago o en La Habana debajo de una palmera con una botella de ron: no, eso les va saliendo. Y claro, ojo, las grabaciones de Palmieri con la All Stars entre el 60 y el 64 se hacían entre las 4 y las 9 de la mañana, después de que habían terminado sus presentaciones profesionales. Seguramente llegaban ebrios, estaban embalados, derecho se amanecían tocando. Estaban jóvenes, tenían vitalidad, querían conquistar un nombre, un nicho en el mercado. La música era su salvación. Yo me baso para esa tesis de la representación del tiempo en el texto de David Harvey, un geógrafo norteamericano que escribió un libro «The condition of postmodernity», «La condición de la postmodernidad», donde desarrolla una teoría sobre la representaciones del tiempo y del espacio en el origen de la modernidad, desde el Renacimiento hasta los años 80 . No habla de salsa, por supuesto, sino de mapas, fotografía, pintura, arquitectura, cine, cómo a través de todas las artes se ha representado el tiempo y el espacio y analiza los cambios en 5 siglos. Lo había leído en el 90, en el Brasil. $Y$ ahora investigando para mi libro y comparando El Manicero encuentro una cierta complementariedad entre lo mío y las tesis de Harvey.

T. Bueno, Alejandro, «la salsa en discusión». La discusión es fuerte con Rondón aunque un poco menos con Ángel Quintero. Cuáles serían en síntesis los puntos de discordia con Rondón y con Quintero.

U. Primero: ambos sitúan la salsa a finales de los 60 y comienzos de los 70. Segundo: ambos hacen mucho énfasis en el sonido del trombón, que es conocido como el sonido de Nueva York (los trombones incorporados por Eddie Palmieri, un sonido agresivo, agrio, disonante, que expresa una cierta irreverencia. No se habían tocado antes ni en la música cubana ni en el jazz. Los trombones son roncos rrrrrrrrrrr, parecen un camión por una avenida, una locomotora en marcha. Yo creo que hay canciones de los Palmieri cuya intención es reproducir el sonido de la calle. Significan «aquí estoy yo», es un grito desesperado que se quiere hacer escuchar en la calle). Ellos -Rondón y Quintero- hacen mucho énfasis en ese sonido pero el sonido de la salsa no se puede reducir al sonido de Nueva York porque en la salsa hubo trompetas, saxos, vibráfonos, violines, combinaciones de muchos instrumentos. Tercero, el espacio: yo hago descripción empírica, ellos no. Rondón llama a esta música «música del Caribe urbano» pero no explicita qué es el Caribe urbano. Uno no sabe si el Caribe urbano es un territorio, y cuál es; si es una población, cuál. Mejor dicho, lo menciona pero no lo conceptualiza.

T. A su favor hay que decir que es un libro de 1979. 
U. Sí, claro, son 30 años y en aquel momento no se tenía toda la información actual. Ese libro de Rondón puesto en perspectiva sigue teniendo un valor extraordinario. Lo reivindico y lo rescato. Lo que pasa es que desde ahora se puede tener una mirada crítica. Es el mejor homenaje. Cuestiono eso porque en la salsa tenés música jíbara puertorriqueña del siglo XIX, música negra puertorriqueña del siglo XVIII, música guajira campesina de los siglos XVIII y XIX, como el son, música urbana del siglo XX como el guaguancó en La Habana o la plena de Puerto Rico, que es del proletariado urbano del siglo XX, tenés el rythm and blues que es música negra americana (el boogaloo es una fusión entre la guajira cubana, el son cubano y el blues y el rythm and blues hecho por newyork-ricans; una segunda generación de newyork-ricans que ya no habla español, nace hablando inglés y son más americanos que latinos: siguen oyendo a Matamoros y a Daniel Santos pero también están oyendo toda la música negra que se está produciendo en Nueva York).

Entonces, cuál es el Caribe urbano. Mucha gente utiliza la expresión así, la copian pero no saben qué están diciendo. A qué se llama «música del Caribe urbano" cuando tiene un poco de jazz, de soul, de blues, de guaracha, de son montuno... T. Y cuáles son tus diferencias con Quintero. U. Dos. Una: en la diferencia de los 10 años, porque él se pega mucho a Rondón. Dos: él dice que la salsa es una manera de asumir la música (en este caso sigue también a Rondón) antes que un género determinado por unas prácticas (que son la libre improvisación en los instrumentos y en el canto). La libre improvisación en el canto ya la habían hecho los cubanos, es una tradición muy fuerte, el soneo, el pregón (también la tienen los brasileros, o la tenían porque tiende a desaparecer, con el Partido Alto, como dicen ellos, en el samba. Es una herencia de los negros esclavos que se enfrentaban en duelos verbales). Pero no podés reducir la salsa sólo a algunas prácticas independientes de los productos. Me parece que Quintero hace una separación abrupta entre los dos y deja de lado la música para concentrarse más en las prácticas. Yo digo que hay que darle igual importancia a ambas. Y en la música están tanto la lírica (es decir, la letra) como los modos de cantar, como los modos de tocar, como la estructura de la pieza ejecutada. Uno no puede separar la forma de los contenidos. Yo cuestiono: ¿La salsa es sólo una manera de hacer música? Si es una manera de hacerla, entonces qué del producto.

T. Como decíamos en los años 60: si alguien no está de acuerdo con el contenido, pues que publique sólo la forma.
AMBOS: ja, ja, ja.

T. Veamos otra dimensión de tu libro. Hay en él una referencia diseminada sobre música brasilera, el tango, el rock and roll. Cuál es la pertinencia de estas referencias.

U. La pertinencia con el rock and roll y el bossa nova se debe a que son simultáneas en el tiempo. Aparecen en la transición de los 50 a los 60 . Es interesante. Habría que indagar más en la historia del rock and roll y no la conozco bien, pero me parece que allí empieza a darse lo que yo llamo «la postmodernidad en la música popular», que consiste en esta transgresión de los géneros, porque es romper con los límites entre ellos. Lo del bossa nova es más claro porque es el samba carioca influenciado por el jazz. Surge en 57 y es creado por un grupo de músicos cultos de clase media urbana de Rio de Janeiro que se reúnen en Copacabana y en Ipanema, frente a la playa, en reuniones muy intimistas, a experimentar. $Y$ como son cultos porque han estudiado y han oído toda la música popular del Brasil y el jazz, comienzan a recrear bajo la influencia de éste y hacen del samba menos énfasis en el ritmo y más en la armonía: menos percusión y algo más elaborado en términos armónicos. Que la salsa, el bossa nova y el rock and roll surjan en ese contexto de hibridación musical, de ruptura de esquemas genéricos y de relaciones internacionales se vuelve sintomático desde el punto de vista cultural. Claro, el primer antecedente es el de la música cubana con el jazz. Después se vienen todas las hibridaciones en cadena. Pero en los 40, cuando se fusionan música cubana y jazz, allí se da el primer ensamble fuerte. Luego viene lo del rock and roll, lo del bossa nova. Ahora, lo del tango se relaciona porque es en el barrio donde se desarrolla un género musical y una cultura musical alrededor de ese género.

T. Siempre en lugares pequeños, entre amigos, entre familia, en el barrio...

U. Y siempre en lugares urbanos. Entones el tango es en los barrios de Buenos Aires: la Boca, El Retiro, Corrales Viejos, por ahí por las orillas del río, ¿vos conocés Buenos Aires?

T. Sí, claro.

U. Bueno, cuando estuve allí indagué por esos barrios y los recorrí, aunque por supuesto hoy son distintos a lo que fueron hace 100 años. Además está documentado. Inclusive en letras de tango aparecen los nombres. Son barrios marginales, los conventillos (los que aquí en Colombia llamamos «inquilinatos») donde convergían el desarraigado, el malandro, el carnicero, el orillero, el de la periferia. En New Orleans, el jazz nace en... ¿dónde es que nace? 


\section{T. ¿En el vieux carré?}

U. No, hombre, lo cuenta Louis Amstrong en... su biografía. Bueno, siempre viene de la marginación. Lugares pobres, siempre excluidos, donde hay negros, prostitución, ladrones... Yo creo que tiene que ver de nuevo con el tiempo pues en la medida en que esta gente y estos músicos no son absorbidos por la maquinaria industrial del capitalismo, no son sometidos a la productividad y a la rapidez, tienen entonces una relación con el tiempo más relajada para producir su música.

T. Es la condición misma de la creación. No sólo en la música.

U. En la cocina, una obra literaria, un poema. La pertinencia está entonces también por el lado del barrio como un epicentro generador de cultura musical y de una música y estilos de vida. Vos cogés los barrios de La Habana, el Santurce en San Juan de Puertorrico, el Story Ville en New Orleans (así es que se llama, Story Ville, qué berraquera): siempre está el negro presente. Incluso en el mismo tango en Buenos Aires. Tango se llamaba a los barrios de tambor que había en Buenos Aires cuando había en esa ciudad una presencia negra, que la había más en Montevideo.

T. Sí, claro. El candombe sigue teniendo allí una gran vigencia, el carnaval es de gran fuerza popular.

U. Por eso el tango nace en las dos ciudades. Aunque los argentinos no sé si lo acepten; ellos... como siempre se han llevado.... Mejor dicho... No hablemos... AMBOS: (Risas estruendosas) ja, ja, ja.

T. Por qué en el libro vas y venís permanentemente entre Nueva York y Cali. Metafóricamente, se entiende.

U. Es a propósito. Por un lado, una intención de decir que esto está escrito desde Cali, que la presencia de la salsa en esta ciudad no es gratuita ni artificial ni una impostura.

T. Una reivindicación territorial de Cali.

U. Sí. Por otro lado mostrar cómo esa música se producía allá y al otro día estaba aquí. No sé si vos te acordás de «Hay una discusión en el barrio»: salió en el 62 y ya sonaba desde el...

T. 61.

(Risas).

U. Sí. Yo me acuerdo de «Qué gente averigüá» (cantando: «Qué gente averiguá, qué gente averiguá»).

AMBOS, CANTANDO EN DÚO: «Que gente averiguá, camará, y nunca me han dado na».

U. Vos te acordás que eso salió en el 61,62 y lo escuché de niño recién salió al mercado. 0 esa otra canción «A Dolores, la pachanguera»...

T. Sí, claro.

AMBOS (CANTANDO): «A Dolores, la pachanguera, su mamá, le dio una pela, por andar, bailando pachanga, por allá, por la carretera».

U. Yo recuerdo haberlo oído en el 63 en el barrio Las Acacias y haberlo bailado, hermano, en «Mi Ranchito» en el barrio La Unión, donde terminaba Cali por ese lado.

T. Por dónde llegaba esa música, ¿por Buenaventura?

U. Sí. Pero creo que hay que averiguar también cuáles eran las redes de distribución discográfica aquí en Cali en ese momento. Si uno mira, desde el año 25 tenés el almacén de la RCA Víctor en la Plaza de Cayzedo ocupando los primeros almacenes comerciales ligados con una multinacional. Es la RCA Víctor al lado de los automóviles Ford 1925, 28. Ahí está. Creo que en los 60 debía haber almacenes de discos que distribuían lo que llegaba. Y efectivamente lo que traían los marineros por Buenaventura. Ese comercio se movía vía aérea o vía marítima. Sí sé que había comerciantes informales que iban a Buenaventura, compraban los discos y luego los traían acá. 
T. Me pregunto si no había una línea de radiodifusión que permitiera piratear.

U. No. En los años 50 sí había una emisora mexicana y otra cubana en onda corta, la CMQ y la XEW de México. Onda corta, no todo el mundo la tenía en los 50; pero para grabarlo lo veo difícil. Lo otro es que haya sido a través de la gente que iba a Nueva York.

T. Los 60 fueron años de intensísimo cruce de gente en los dos sentidos.

$\mathrm{U}$. Y fue mucha gente de Cali.

T. Bueno, había consulado de Estados Unidos en Cali.

U. (En voz baja, furtiva) Donde quemamos la bandera.

(SILENCIO. RISAS CONTENIDAS)

T. Sí. Lo que hace esto interesante es que debía haber una gran sensibilidad musical en los años 60 no sólo para que la gente aceptara, bailara, reprodujera sino también para que existieran circuitos de comercialización tan eficientes para que en lapsos tan breves ya estuviera la música neoyorkina aquí. Obedece sin duda a razones culturales muy antiguas y profundas cuya extensión, profundidad y valor no han sido suficientemente estudiados. Recordá la referencia que hacíamos hace un rato a El Alférez Real. Pero también habría que explorar en María, de Jorge Isaacs.

U. Para no ir tan atrás: había una memoria musical consolidada en Cali desde los 40 y los 50 de música cubana y puertorriqueña afincada en esta ciudad. Toda la música de Daniel Santos, Bobby Capó, Pedro Flórez, Rafael Hernández, Matamoros, Cuarteto Victoria, Trío Borinquen, el Cuarteto Mayarí....Benny Moré, Sonora Matancera... Casino la Playa, Miguelito Valdés... Todo eso sonaba aquí, se bailaba, se practicaba. Era en la llamada «zona de tolerancia». Allí era el hervidero, la efervescencia, pues esa música también se asociaba con negros, con malandros, con marihuaneros, con putas, con bandidos, con ladrones y futbolistas. Todo en ese barrio, que era el Sucre, se expande en los 60, 70 por el Obrero, San Nicolás, y luego por toda la ciudad.

T. Recuerdo muchos bares que tenían un baterista que seguía la música. U. Sí, la acompañaba. Muy singular, pues mientras en Puerto Rico, en Cuba, en Nueva York tenían una orquesta, aquí teníamos un baterista: una metonimia, la parte por el todo. Era muy usual en los bares de la zona de tolerancia. Incluso lo hay todavía en algunos bailaderos.

T. Alejandro, abordás en la parte final del libro los nuevos formatos. En particular me interesa escuchar tus criterios en torno a lo que llamás la «salsapacífico».

U. La salsapacífico es una categoría que estoy proponiendo para designar una nueva vertiente de la salsa que se hace con músicos de la costa Pacífica colombiana, particularmente Chocó, Buenaventura, y que tiene ciertos elementos ingredientes de la cultura musical del Pacífico. Por un lado el vínculo con el currulao y otros aires del folklore del Pacífico. Es una música ternaria,

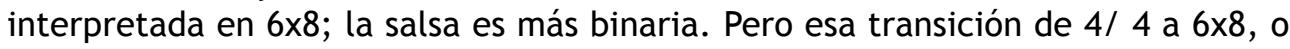
al revés, los músicos la resuelven de una manera relativamente fácil. Pero más allá de pensar que es una fusión intergenérica, hay otros elementos que tienen que ver con la melodía. La gente del Pacífico, Tumaco inclusive, siempre oyó la música caribeña de los años 40. Cartagena, Atrato, Quibdó y demás pueblos: esa era la ruta. Por aquí llegaba por Buenaventura. Siempre oyeron Matamoros, Miguelito Valdés, Casino de la Playa, la Riverside, la Sonora, Cortijo... desde niños escuchaban esa música en la cotidianidad. Esas melodías más las propias tradicionales (el currulao, los bundes, los alabaos ( $\mathrm{y}$ en el caso de Chocó melodías que vienen de Francia e Inglaterra, como la contradanza y el minuet... Vos sabés que en Chocó hubo hasta piratas ingleses y franceses, sobre todo ingleses...). 
T. Yo tuve una enfermera cuando me operaron en el ISS en los años 70, una negra gigantesca con unos brazos enormes, que se llamaba Elizabeth Taylor (AMBOS RIEN)...descendiente de piratas ingleses, con seguridad.

U. Entonces, en el Chocó hubo mucha influencia francesa, española e inglesa porque llegan buscando el oro. Traían su música. En el Chocó es el único lugar donde encontrás un bombardino. Encontrás clarinete y bombardino en un formato que tiene también otros instrumentos de viento como el trombón.

T. De hecho, le escuché a... cómo se llama ... ¿Nino Caicedo? que estudiaba en el colegio en Chocó con un cura español que traía partituras de música española.

U. Ese mismo cura le enseñó a Jairo Varela y a Alexis Lozano. Te decía que la contradanza, que es de origen francés e inglés, el minuet, la polka, el chotis, géneros de la música popular en el siglo XIX, están en el Chocó. Entonces hay una memoria que no está hecha sólo de la música del Caribe, de la música colombiana de la costa Pacífica sino también de música europea. $Y$ cuando el compositor compone la melodía, que es lo más importante, ya después el ritmo y la armonía es relativamente sencillo, a pesar de que, por supuesto, reviste un grado de complejidad. El problema es de dónde te sale la melodía. La melodía te sale de una memoria cultural musical. Y el que tiene la inteligencia musical -yo creo que es innata; no todos podemos ser músicos-, el que es músico natural en el Pacífico produce de acuerdo con la memoria del Pacífico. Por otro lado están las maneras de cantar, que es algo muy ligado a la manera de hablar, a lo que se llama los «dialectos regionales", y los dialectos sociales. Hay unas maneras de cantar ligadas al timbre como a los dialectos. Un negro del Pacífico no puede cantar como un cubano. Hay unas maneras de cantar ligadas a ciertas maneras colectivas de cantar en la región. Hay ciertas expresiones del habla que se incorporan a las canciones y que hacen referencia al Pacífico, a sus personajes, a sus territorios, a sus costumbres, a su contexto cultural. Para mí ésa es la salsapacífico.

T- ¿Encontrás especificidades rítmicas?

U. Pero eso hay que oírlo. Por ejemplo, «Son cepillao con minuet», 1987, por Alexis Lozano, comienza como una contradanza tan tan tan tan, luego hay un corte, es tatatatata ritmo viejo pun pun pun pun de mis abuelos. Ahí está, es la presencia de la contradanza en el Chocó. Y más recientemente hay otras, Jimmy Saa... Eso es lo que estoy investigando. Yo les pregunto a muchos y no saben explicarlo.

T. Pues claro, lo viven. No lo han racionalizado.

U. Sí, no lo han racionalizado. Yo los estoy como forzando a que lo racionalicen.

T. Y quizás la racionalización no venga de ellos. U. No, viene más de afuera. Lo que pasa es que se necesita ser músico y yo tengo una limitación muy berraca. Yo he hablado con músicos que me dicen... Un licenciado de música de la Universidad del Valle hizo su tesis de grado sobre el currulao, primera tesis sobre el currulao; en un seminario que hicimos decía que no era posible, que era incompatible el currulao con la salsa porque el currulao era música ternaria y la salsa era binaria. Se podía hacer con ciertos aires no ternarios sino binarios. Pero Jaime Henao me decía que sí se puede por amalgamas de compases. Andrés Viáfara me decía también, a ver busco en este libro, (BUSCA)... trato de entender muy intuitivamente... tenés una base rítmica del currulao que es de $6 \times 8$ (TOCA EN LA MESA)... si la tenés, podés montar una melodía que no corresponda a ese ritmo sino a otro... una superposición de dos planos. Y luego se puede pasar de uno a otro. Lo que se debe mantener es la clave, que es fundamental en la salsa, la clave en $2 \times 3$ o en $3 \times 2$. Viáfara, el arreglista, ese man le arregla a todo el mundo, (VACILA, BUSCA), ah, acá está, "se puede pasar del $6 \times 8$ al cuatro cuartos, se puede meter el $6 \times 8$ sobre el cuatro cuartos sin cambiar el $6 \times 8$. Hay otros ritmos del Pacífico que no son $6 \times 8$, como el alabao y el río abajo, que son $4 / 4$, por lo tanto más compatibles con la salsa. 'Mi Buenaventura' está hecho originalmente en $4 \times 4$ por Petronio Alvarez; Peregollo lo grabó en $6 \times 8$ y yo lo grabé en $4 \times 4$ para Luis Mosquera. Ahora Jimmy Saa con arreglo de Tarry Garcés comienza en 6x8 y luego cambia a 4x4". Mirá lo que dijo Bobby Valentín en la primera entrevista que le hice hace 20 años, Valentín, el arreglista de la Fania... Para mí ese señor... A ver busco... Aquí: «Sobre la base del piano, bajo, conga, timbales y bongó, que constituyen el ritmo en la salsa, puede añadirse cualquier instrumentación (cuerdas, sintetizadores, metales...), pueden escribirse diferentes fraseos, frases clásicas en músicas típicas (Bambucos, currulaos..), jazziadas, semiclásicas, folklóricas, lo que el músico quiera, pero hay que darle color y saber en qué momento hacerlo sin perder el ritmo. Pueden usarse diferentes compases, el $6 \times 8$ afrocubano, el $3 \times 4$, el $2 \times 4$ o el $4 \times 4$ que se usa en la salsa bailable». $\mathrm{Si}$ estos dos músicos coinciden en decirlo... 
T. Pero Valentín no dice eso. El dice que pueden darse separadamente, no habla de la hibridación de la que hablamos ahora.

$\mathrm{U}$. Bueno, tal vez tengo que volvérselo a preguntar ahora con base en esto a ver cómo se resuelve; pero creo que está implícito en su declaración.

T. Qué legitimaría el uso del término «salsa» en la expresión «salsapacífico».

U. Para mí el hecho de que esté hecha por los músicos del Pacífico provistos de esa memoria musical: la salsa del 60 para acá más los elementos del folklore, y la presencia de la clave más la polirritmia de la percusión...

T- Qué edad tiene Varela.

U. ¿Jairo Varela?

T. Sí.

U. Yo creo que ese man llega a los 50 ya.

T- ¿Y Lozano?

U. También. Por ahí.

T. Son nacidos a finales de los 50 .

U. Sí. Lo mejor para entender esto es escuchando la música.

T. Sí. Y con un vaso de whisky en la mano, como Vinicius de Moraes.

U. Sí, o de ron...

T. Una última pregunta, Alejandro (además ya estamos cansados, ¿no?). La música nace y muere. Nadie hoy compone polkas ni bambucos, aunque en este país todo es posible. Hacia cuál futuro se encamina la salsa.

U. Veo como tres ramificaciones. Una, la salsapacífico, que no la hace sino la gente del Pacífico, Chocó, Buenaventura y Cali. Es una vertiente muy renovadora. Claro, depende de los músicos pues si se acomodan y caen en el facilismo, no pasa nada. Si lo asumen como un riesgo, como un reto, lo veo como una cosa muy promisoria y sería nuestra gran contribución a la salsa desde aquí. La segunda es la de la hibridación más universal (con la timba, con el pop, con el reggueton), que es lo que está experimentando mucha gente como la 8 y $1 / 2$ de Francia. La timba cubana que está emparentada con la salsa y ciertas fusiones entre salsa y timba. $Y$ una vertiente más ortodoxa que se sigue haciendo ya no tanto ni en tantas cantidades, pero se sigue haciendo, como Bailatino en Venezuela. Es una salsa más ortodoxa, bien elaborada. También la hacen algunas orquestas de Cali.

T. Acabo de oír Calambuco, una salsa bien hecha, clásica.

U. Varios son músicos de aquí que trabajan en Bogotá. También se hace en Europa, Francia, Holanda, España, con grupos constituidos por colombianos, venezolanos, latinos, algunos europeos; tocan una salsa más clásica. Veo como esas 4 vertientes, no las 3 de que hablé: ortodoxa, la salsapaífico, la salsa fusión con timba y otra más abierta a todos. Yo agregaría la salsa de Marc Anthony y la salsa balada. Son finalmente como 6.

T. Estas dos últimas obedecen más a dinámicas comerciales incentivadas más por una estrategia económica que por una fuerza cultural telúrica. U. Es más la fusión con el pop americano, con ciertas maneras de tocar música electrónica, incluso de tocar el bajo, la percusión. Uno siente allí ciertas particularidades que no encuentra en la salsa ortodoxa. La salsapacífico sí está mucho más enraizada en la cultura. Cuando vos tenés a músicos como Hugo Candelario, de Guapi, Andrés Viáfara, Yuri Buenaventura, Jimmy Saa, que son de Buenaventura, que han comido mierda, que vienen de la pobreza, que vienen de abajo, que han sido gozones, que han oído música, etc. etc. etc., te das cuenta que están respaldados por una trayectoria...

T. Por una historia cultural.

U. Sí, por una historia cultural. Yo veo allí una cantera muy interesante. Jairo Varela dice que no hace salsa colombiana, que hace salsa, a secas. Pero, hermano, no es lo que él diga sino lo que dice la música que él hace.

T. Claro, como en todo, uno se guía por lo que dicen los productos.

U. Por sus obras los conoceréis, como decía... ¿quién? Jajajaja.

T. Jajaja. Bueno, Alejo, creo que hemos hecho un buen trabajo. 